Cell Research (2000), 10, 233-242

\title{
Expression of Bcl-2 inhibited Fas-mediated apoptosis in human hepatocellular carcinoma BEL-7404 cells
}

\author{
Chang Yun Chao, Yong Hua Xu* \\ Shanghai Institute of Cell Biology, Chinese Academy of Sciences, \\ 320 Yue-yang Road, Shanghai 200031, China
}

\begin{abstract}
Apoptosis plays an important role in embryonic development, tissue remodeling, immune regulation and tumor regression. Two groups of molecules (Bcl-2 family and "Death factor" family) are involved in regulating apoptosis. In order to know about the effect of Bcl-2 on apoptosis induced by Fas, a typical member of "Death factor" family, the transfection experiments with expression vectors pcDNA3$\mathrm{fl}$ and pcDNA3- bcl-2 were performed in BEL-7404 cells, a human hepatocellular carcinoma cell line which expresses endogenous Fas, but not FasL and Bcl-2. The data showed that the expression of FasL in pcDNA3- fl transfected hepatoma cells obviously induced the apoptosis of the cells. However, the overexpression of Bcl-2 in pcDNA3- bcl-2 transfected 7404/ b- 16 cells counteracted pcDNA3- $\mathrm{fl}$ transient transfection mediated apoptosis. Further study by co-transfection experiments indicated that Bid but not Bax (both were pro-apoptotic proteins of Bcl-2 family) blocked the inhibitory effect of Bcl-2 on Fas-mediated apoptosis. These results suggested that Fasmediated apoptosis in human hepatoma cells is possibly regulated by Bcl-2 family proteins via mitochondria pathway.
\end{abstract}

Key words: Apoptosis, FasL, Bcl-2, Bid, Bax, human hepatocellular carcinoma cells.

\section{INTRODUCTION}

Apoptosis, or programmed cell death, is an innate mechanism by which the organism eliminates unwanted cells. It plays an important role in embryonic development, tissue

\footnotetext{
* Corresponding author: e-mail: yhxu@sunm.shcnc.ac.cn
} 
Bcl-2 inhibited Fas-mediated apoptosis

remodelling, immune regulation and tumor regression. Cells undergoing apoptosis show a sequence of morphological changes including membrane blebbing, cellular shrinkage and condensation of chromatin. In addition, activated DNA endonuclease in apoptotic cells can cleave genomic DNA into internucleosomal fragments, giving "DNA ladder" in agarose gel.

Higher organisms have developed several mechnisms to eliminate cells by apoptosis. An important mechanism to regulate apoptosis is the signaling pathway mediated by "Death factors" including TNFR1, Fas and TRAILR1 and their cognate ligand (TNFa, Fas Ligand and TRAIL) [1]. Fas (also called APO-1, CD95), the first identified member of "Death receptors", is a $45 \mathrm{kDa}$ type I glycoprotein expressed on cell surface. Crosslinking of Fas by its ligand FasL binding leads to conformational changes of Fas, which results in formation of DISC (death induced signaling complex) followed by activation of caspase- 8 . Then activated caspase- 8 activates itself and other caspases. These activated caspases induce apoptosis by cleaving their substrates. It is found that Fas is expressed in many tumor cell lines and may mediate apoptosis induced by FasL or agonistic anti-Fas antibody.

Members of Bcl-2 family are also involved in regulation of apoptosis. Bcl-2 is an inhibitor of apoptosis whose expression can inhibit apoptosis induced by many signals such as ultra-violet radiation, anti-tumor drugs and deprivation of growth factors[2]. Effects of Bcl-2 expression on Fas-mediated apoptosis are different in several lymphoma cell lines[3],[4]. Scaffidi C. et al. classified them into two kinds of cells (Type I and Type II cells)[5]. Ectoexpression of Bcl-2 inhibited Fas-mediated apoptosis in Type II but not Type I cells. However, there are not many studies on this issue in solid tumor cell lines.

The aim of this study is to examine the effect of Bcl-2 on Fas-mediated apoptosis in human hepatoma cells. In our study, we used a human hepatocellular carcinoma cell line BEL-7404 which expressed Fas antigen but not FasL and Bcl-2. By transient transfection with expression plasmid pcDNA3- fl, we constructed a model of Fas-mediated apoptosis. We also found that expression of Bcl-2 in BEL-7404 cells was able to inhibit Fas-mediated apoptosis. Further study suggested that overexpression of Bid but not Bax blocked the inhibitory effect of Bcl-2 on Fas-mediated apoptosis.

\section{MATERIALS AND METHODS}

\section{Construction of expression plasmid}

The $900 \mathrm{bp}$ fas ligand cDNA fragment containing intact ORF was digested by XbaI from pBXfasl vector (gift of Professor Nagata S), and inserted into the XbaI site of pcDNA3.0 (Invitrogen) to generate an expression plasmid pCDNA3- fl. The correct orientation was confirmed by SacI digestion. $1.6 \mathrm{~kb} \mathrm{Bcl-2}$ cDNA (gift of Doctor Yin DL) and $600 \mathrm{bp}$ bax cDNA (gift of Professor Korsmeyer SJ) fragment was inserted into EcoRI site of pcDNA3.0 to generate expression vectors pcDNA3- bcl-2 and pcDNA3- bax respectively. bid cDNA was amplified by RT-PCR from human normal liver and inserted into EcoRI and BamHI sites of pcDNA3.0 to generate pcDNA3- bid. 


\section{Cell culture and establishment of cell lines}

Human hepatocellular carcinoma cell line BEL-7404 (Shanghai Cell Bank, Chinese Academy of Sciences) was maintained in Dulbecco's modified Eagle's medium (DMEM, GIBCO) supplemented with $10 \%$ newborn calf serum (Evergreen, Hangzhou, P.R.China), 100 units/ml penicillin and $100 \mu \mathrm{g} / \mathrm{ml}$ streptomycin. Cells were subcultured at 70-80\% confluence and culture medium was changed every 2 or $3 \mathrm{~d}$ to maintain good growth condition. To establish BEL-7404 cells with highly expressed Bcl-2 protein, BEL-7404 cells were transfected with pcDNA3- bcl-2 by calcium phosphate precipitate method[6]. The cells were cultured for 3 weeks in selection medium $(400 \mu$ $\mathrm{g} / \mathrm{ml}$ Geneticin, SIGMA) to select stable transfectants. BEL-7404 cells were also transfected with pcDNA3.0 to obtain control cells. Individual clones were picked up at random and amplified. The expression of Bcl-2 protein was determined by western blot analysis.

\section{Transient transfection (by electroporation method)}

The apparatus used in the experiments was Gene Pulser ${ }^{T M}$ (BIORAD). Cells growing to exponential stage were pooled, rinsed twice with D-Hanks saline solution and suspended in DHanks at 0.5-1.0 $\times 10^{7}$ cells $/ \mathrm{ml}$. Plasmid was added to final concentration $50 \mu \mathrm{g} / \mathrm{ml}$ and incubated on ice for $10 \mathrm{~min}$. Then cells were electroporated one time at $600 \mathrm{~V}, 25 \mu \mathrm{F}$ and $100 \Omega$ and incubated on ice for another $10 \mathrm{~min}$. Appropriate amount of cells were inoculated into DMEM and grew at $37{ }^{\circ} \mathrm{C}, 5 \% \mathrm{CO}_{2}$. For co-transfection, the ratio of two plasmids was 1:1.

\section{RT-PCR analysis}

Total RNA isolation and RT-PCR was based on Zhao' s method[7]. In brief, $2 \mu \mathrm{g}$ total RNA extracted from cells was reverse transcribed using $200 \mathrm{ng} 6$-mer random primers in a volume of $20 \mu \mathrm{l}$ for $1 \mathrm{~h}$ at $37{ }^{\circ} \mathrm{C}$ water bath. Then $1 \mu \mathrm{l}$ reverse transcription products was used for PCR. In a total of $25 \mu \mathrm{l}$ reactive mixture, 10 pmol forward primer and 10 pmol reverse primer, $1 \times$ reaction buffer and 1 unit Taq polymerase were mixed. The reaction was run for 30 cycles, each consisted of denaturation at $94^{\circ} \mathrm{C}$ for $30 \mathrm{~S}$, annealing at $55^{\circ} \mathrm{C}$ for $30 \mathrm{~S}$, and extension at $72{ }^{\circ} \mathrm{C}$ for $60 \mathrm{~S}$ and Final extension prolonged for $10 \mathrm{~min}$ at $72^{\circ} \mathrm{C}$. The primer for fas sequence was: forward, 5 ' GAT TGC TCA ACA ACC ATG-3'; reverse, 5' -TTT CAC TCT AGA CCA AGC TTT G-3, (1029bp). The primer for fasl sequnce was: forward, 5' -CGA GAG TCT ACC AGC CAG ATG C-3'; reverse, 5' -TCC CAA AGT GCT TCT CTT AGA GC-3' (450bp). The primer for $\beta$ actin sequence was: forward, 5' -ACA CTG TGC CCA TCT ACG AGG GG-3'; reverse: 5' ATG ATG GAG TTG AAG GTA GTT TCG TGG AT-3' (360bp). The primer for bid sequence was: forward, 5' -ATG GAC TGT GAG GTC AAC-3'; reverse, 5' -AGT CCA TCC CAT TTC TGG-3' (587bp). The primer for bax sequnce was: forward, 5' -CAC CAG CTC TGA GCA GAT G-3'; reverse, 5' -GCG AGG CGG TGA GCA CTC C-3' (516bp).

\section{Western blot analysis}

Protein extraction and western blot was based on Oltvai's method[8]. In brief, cells were washed twice with D-Hanks and lysed in following buffer with freshly added protease inhibitors (142.5 m $\mathrm{M} \mathrm{KCl}, 5 \mathrm{mM} \mathrm{MgCl}$, $10 \mathrm{mM}$ HEPES [pH 7.2], $1 \mathrm{~m} \mathrm{M} \mathrm{EGTA,} 0.2 \% \mathrm{NP}-40$, and $0.2 \mathrm{mM} \mathrm{PMSF}$ ) for $30 \mathrm{~min}$. Nuclei and unlysed cellular debris were removed by centrifugation at $12000 \mathrm{~g}$ for $10 \mathrm{~min}$. Protein concentration was determined by Bradford' s method. For western blot, $10 \mu \mathrm{g}$ of total protein was subjected to $12 \%$ SDS-PAGE and electrotransferred at $4^{\circ} \mathrm{C}$ for $2 \mathrm{~h}$ onto nitrocellulose membrane. After blocking at $37{ }^{\circ} \mathrm{C}$ for $2 \mathrm{~h}$ with TBST (Tris-buffered saline containing $0.5 \%$ Tween-20) containing $5 \%$ nonfat milk, membrane was incubated with anti-Bcl-2 antibody (1: 100 , Sinoamerica Biotech) at $37^{\circ} \mathrm{C}$ for $2 \mathrm{~h}$. Membrane was subsequently incubated with HRPconjuncated second antibody (1:3000, Vector) at room temperature for $2 \mathrm{~h}$. Finally, membrane was developed with diazobenzidine (Amersico) and $\mathrm{H}_{2} \mathrm{O}_{2}$. Membrane was washed with TBST for 4 
Bcl-2 inhibited Fas-mediated apoptosis

times between each step.

\section{PI staining and flow cytometric analysis}

Cells were washed twice with D-Hanks and fixed in sodium citrate at $4{ }^{\circ} \mathrm{C}$ for $30 \mathrm{~min} .5 \mathrm{ml}$ stainning solution (propidium iodide $50 \mu \mathrm{g} / \mathrm{ml}$, RNase $10 \mu \mathrm{g} / \mathrm{ml}$ ) was added to $10^{6}$ cells for $15 \mathrm{~min}$ at $4{ }^{\circ} \mathrm{C}$ in dark. Then cells were examined in fluorescence microscope or analysed by flow cytometric with FACS calibur (Becton Dickinson) and analysis software CELLQest (Becton Dickinson).

\section{DNA fragmentation analysis}

Isolation of low molecular weight DNA was based on Lowe' s method[9]. In brief, adherent and nonadherent cells were pooled, washed with D-Hanks, and resuspended in solution I $(0.15 \mathrm{M}$ $\mathrm{NaCl}, 10 \mathrm{~m} \mathrm{M}$ Tris-Cl [pH7.4], $2 \mathrm{~m} \mathrm{M} \mathrm{MgCl}$, $1 \mathrm{~m} \mathrm{M} \mathrm{DTT}$, and $0.5 \%$ [v/v] NP-40) for $30 \mathrm{~min}$ on ice. Nuclei were isolated by centrifugation at $5000 \mathrm{~g}$ for $5 \mathrm{~min}$, resuspended in solution II $(0.35 \mathrm{M}$ $\mathrm{NaCl}, 10 \mathrm{~m} \mathrm{M}$ Tris-Cl [pH7.4] $2 \mathrm{~m} \mathrm{M} \mathrm{MgCl}$ and $1 \mathrm{~m} \mathrm{M} \mathrm{DTT} \mathrm{)} \mathrm{for} 20 \mathrm{~min}$ on ice. The nuclei were then removed by centrifugation at 5,000 $\mathrm{g}$ for $5 \mathrm{~min}$, and the supernatant was extracted with phenol and chloroform. The low molecular weight DNA was recovered by ethanol precipitation. Samples were resuspended in TE buffer and treated with RNAase A for 30 min prior to electrophorsis on $1.4 \%$ agarose gels.

\section{RESUITS}

\section{Transfection with pcDNA3-fl induced apoptosis in BEL-7404 cells}

Using primers specific for fas and fasl sequences shown in materials and methods, we have detected the expression of fas mRNA but not fasl mRNA in human hepatocellular carcinoma BEL-7404 cells by RT-PCR (Fig 1A). There was a predicted 1029bp fas fragment in BEL-7404 cells (Lane 1), however fasl product was undetectable (Lane 2). In later experiments, BEL-7404 cells were transiently transfected with plasmid pcDNA3 or pcDNA3- $\mathrm{fl}$ by electroporation. Total RNA of cells transfected with pcDNA3 or pcDNA3fl was extracted and used for RT-PCR analysis. As shown in Fig 1B, a specific 450 bp band was only seen in the cells transfected with pcDNA3- fl (Lane 4). This suggested



A

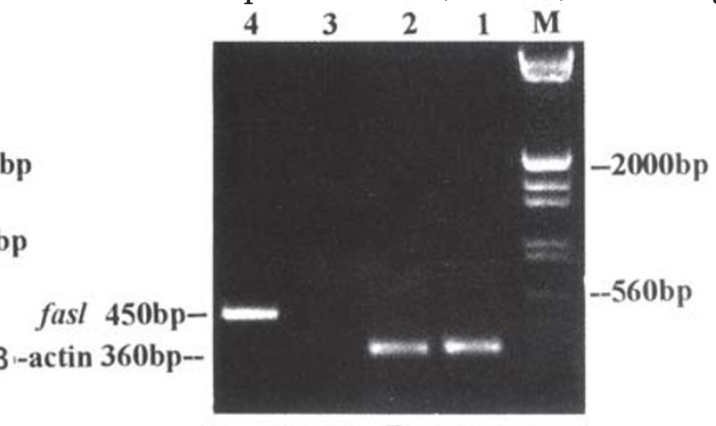

$\mathrm{B}$

Fig 1. A, Detection of fas and fasl mRNA expression by RT-PCR in BEL-7404 cells. Lane 1, amplification of fas. Lane 2, amplification of fasl. B, Detection of fasl mRNA expression by RT-PCR in BEL-7404 cells transfected with pcDNA3- fl. Lane 1, amplification of $\beta$-actin in cells transfected with vector pcDNA3. Lane 2 , amplification of $\beta$-actin in cells transfected with vector pcDNA3- $\mathrm{fl}$. Lane 3, amplification of fasl in cells transfected with control vector pcDNA3. Lane 4, amplification of fasl in cells transfected with vector pcDNA3- fl. 
that fasl expressed in BEL-7404 cells after being transfected with pcDNA3- fl.

As shown in Fig 2, no apparent change of cell morphology occurred in the cells transfected with control vector pcDNA3 (A), but most of the cells transfected with pcDNA3$\mathrm{fl}$ became round and detached from the surface of dishes and underwent apoptosis (B). By PI staining, we also found that the nuclei of cells transfected with pcDNA3- fl were smaller than control group and fragmented into small pieces, which were typical characteristics of apoptosis (compare $\mathrm{C}$ with $\mathrm{D}$ ). In order to study the time effect of transfection with pcDNA3- fl on cell death, cells at different time after transfection were recovered to analyse by flow cytometry. "Sub-G1" cells, which had less DNA than normal cells in flow cytometric analysis, were used to represent apoptotic cells. Results shown in Fig 3 indicated that apoptotic cells occurred $12 \mathrm{~h}(11.9 \%)$ after transfection. Cell death reached to a maximum $24 \mathrm{~h}(26.2 \%)$ and decreased $48 \mathrm{~h}$ after transfection (15.7\%). In addition, typical "DNA ladder" appeared in the DNA extracted from cells $12 \mathrm{~h}$ after transfection.

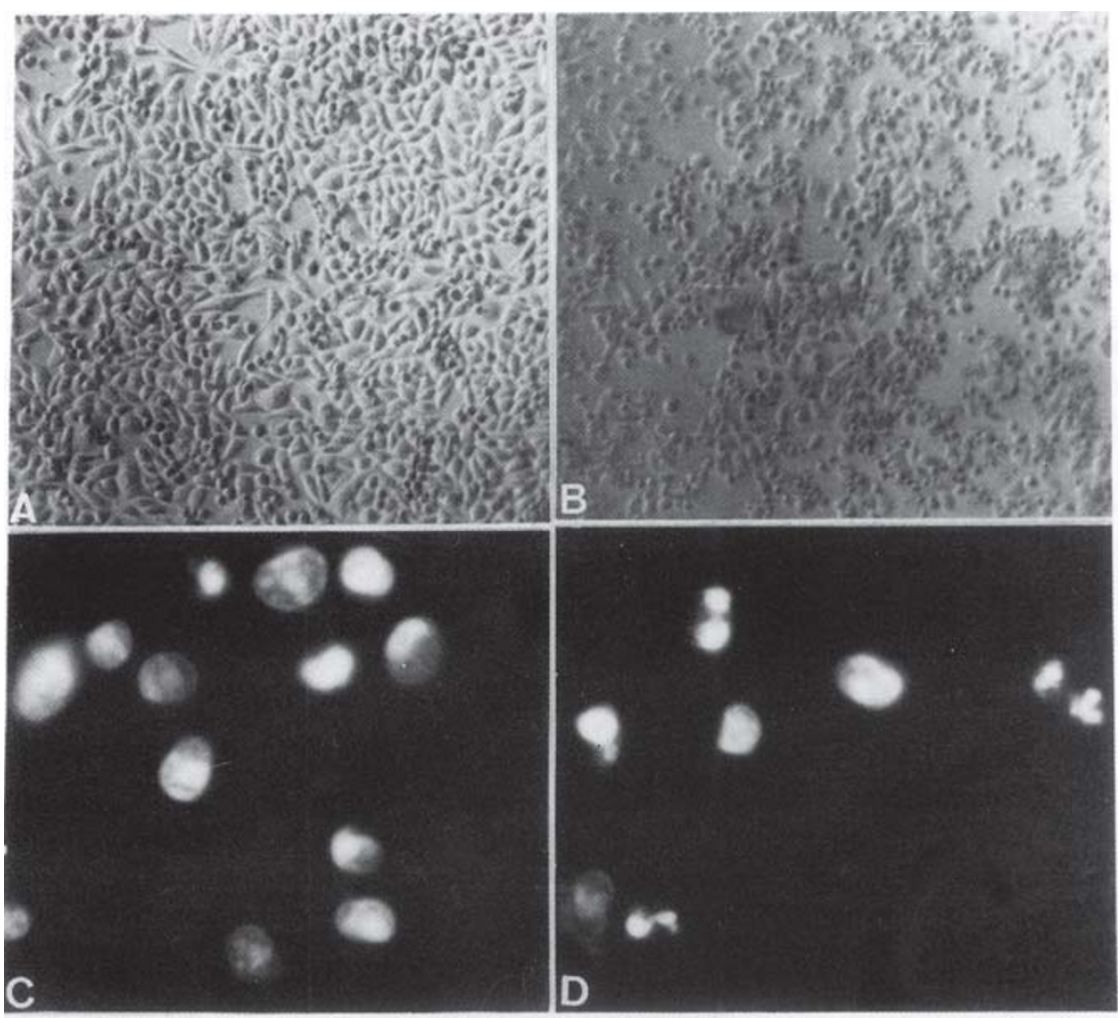

Fig 2. Morphology comparison of BEL-7404 cells and its nuclei at $24 \mathrm{~h}$ after transfection with pcDNA3 or pcDNA3- fl. A) cells transfected with pcDNA3. B) cells transfected with pcDNA3- fl. C) nuclear morphology of cells transfected with pcDNA3. D) nuclear morphology of cells transfected with pcDNA3- fl. 
Bcl-2 inhibited Fas-mediated apoptosis

The DNA fragmentation was obviously more serious 24 and $48 \mathrm{~h}$ after transfection with pcDNA3- fl as compared with control (Fig 4). Taken together, all above data suggested that transfection with pcDNA3- fl induced apoptosis in BEL7404 cells.

\section{Construction of BEL-7404 cell lines with highly expressed Bcl-2 pro- tein}

Recombinant expression plasmid pcDNA3- bcl-2 was transfected into BEL-7404 cells using calcium phosphate precipitate method. Vector pcDNA3 was used as control plasmid for transfection. Through G418 selection, most cells died in 10-14 d, but some cells later formed G-418-resistant cell foci. By random picking, cell amplification and identification by western blot, two cell clones expressing bcl-2 protein were obtained, designated as 7404/b-13 and 7404/b-16 respectively. We also obtained one empty vector transfected clone, named as 7404/neo. Expression of Bcl-2 protein detected by western blot was shown in Fig 5. A specific $26 \mathrm{kDa}$ band was only seen in cell lysates from 7404/b-13 and 7404/b-16 cells (Lane 3 and 4). It indicated that $26 \mathrm{kDa}$ Bcl-2 was expressed in 7404/b-13 and 7404/ b-16 cells but not in parent BEL-7404 and 7404/neo cells (Lane 1 and 2).

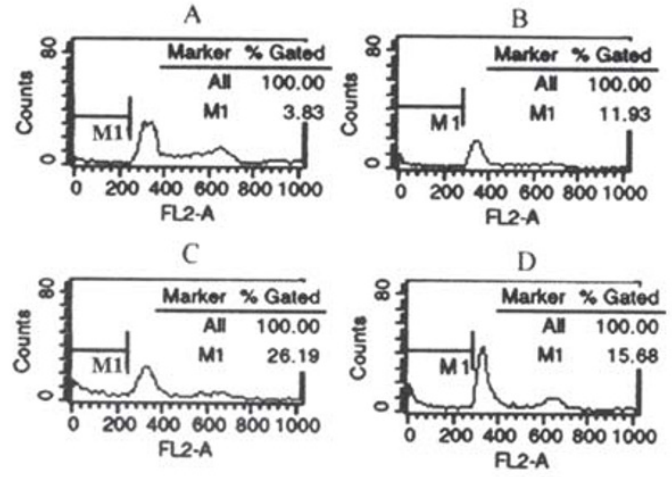

Fig 3. Percentage of "sub-G1cells" in BEL-7404 cells at different time after transfection with pcDNA3- fl. The bar 'M1' was referred “tosub-G1" cells. A, $0 \mathrm{~h}$ after transfection. B, $12 \mathrm{~h}$ after transfection. C, $24 \mathrm{~h}$ after transfection. $\mathrm{D}, 48 \mathrm{~h}$ after transfection.

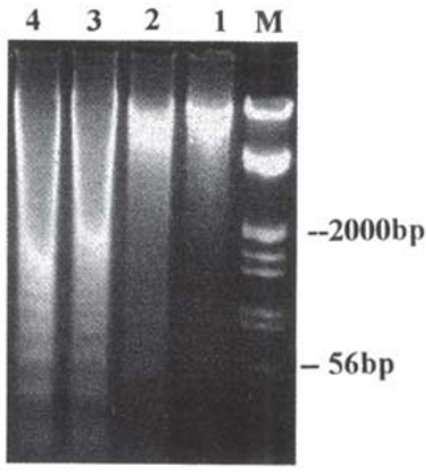

Fig 4. Analysis of low molecular weight DNA from BEL-7404 cells transfected with pcDNA3- fl. Lane 1, DNA of control cells. Lane 2, DNA of cells $12 \mathrm{~h}$ after transfection. Lane 3, DNA of cells $24 \mathrm{~h}$ after transfection. Lane 4, DNA of cells $48 \mathrm{~h}$ after transfection.

\section{Bcl-2 protein inhibited Fas-induced apoptosis in BEL-7404 cells}

In order to examine the effect of Bcl-2-expression on Fas-mediated apoptosis, BEL7404, 7404/neo and 7404/b-16 cells were transiently transfected with pcDNA3- fl or pcDNA3 respectively. Cells were pooled for flow cytometric analysis $24 \mathrm{~h}$ after transfection. As shown in Fig 6, the percentage of apoptotic cells in BEL-7404 and 7404/neo cells trans- 
fected with pcDNA3- fl (25.4\% and $26.1 \%$, respectively) was significantly higher than that transfected with pcDNA3 $(7.1 \%$ and $4.9 \%$, respectively). However, there was no apparent change on the percentage of apoptotic cells between 7404/b-16 cells transfected with pcDNA3 (13.1\%) or pcDNA3- fl (14.3\%). These results suggested that expression of Bcl-2 protein was able to inhibit Fas-mediated apoptosis in BEL-7404 cells.

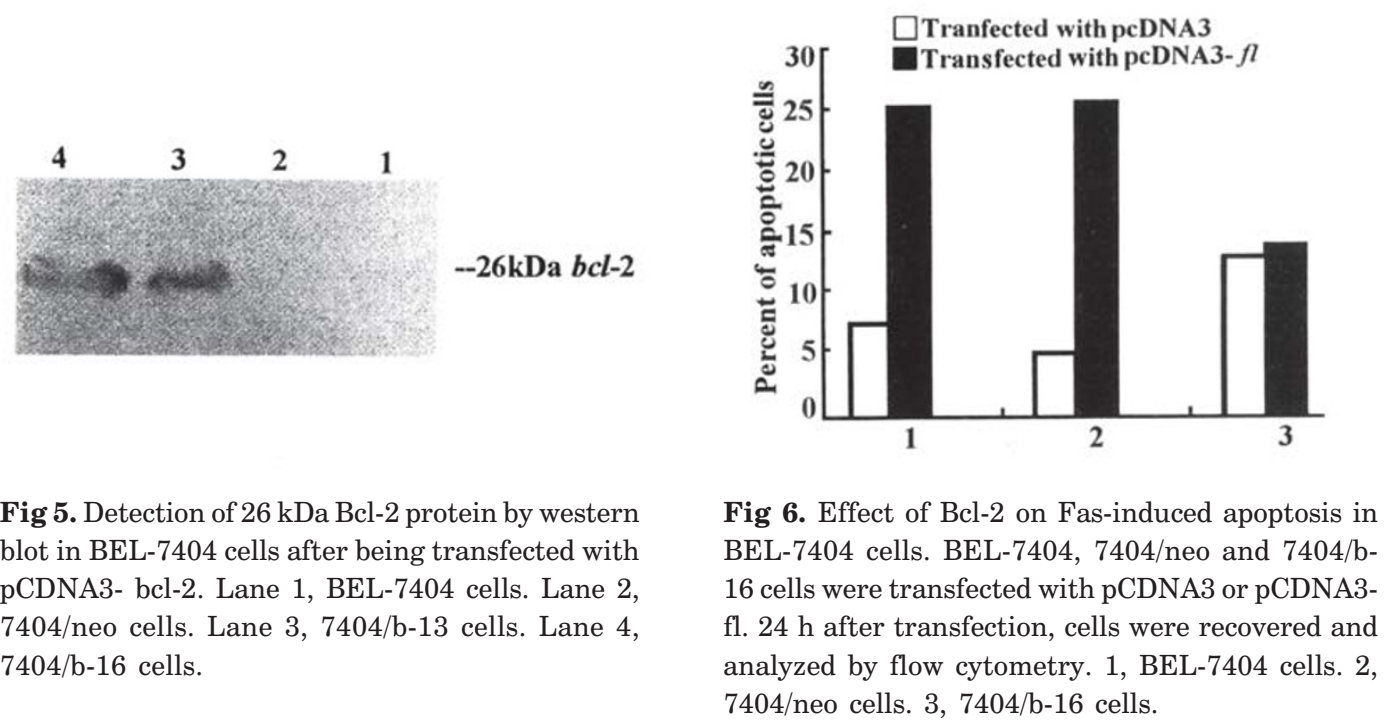

\section{Overexpression of Bid but not Bax counteracted the inhibitory effect of Bcl-2-expression on Fas-mediated apoptosis in 7404/b-16 cells}

Bid and Bax protein are both pro-apoptotic members of Bcl-2 family. We wondered if they were involved in regulating Fas-mediated apoptosis in human hepatoma cells. By cotransfection experiments in 7404/b-16 cells, we examined the impact of overexpression of bid or bax on the inhibitory effect of Bcl-2 on Fas-mediated apoptosis. Fig 7A showed the percentage of apoptotic cells in 7404/b-16 cells $24 \mathrm{~h}$ after co-transfection. It was found that the apoptotic percentage of cells co-transfected with pcDNA3- fl plus pcDNA3- bid (Lane 3, 31.0\%) was much higher than that of cells co-transfected with double amount of pcDNA3 (Lane 1, 13.2 \%) or pcDNA3 plus pcDNA3- fl (Lane 2, 14.1\%). However, there was no apparent difference on the apoptotic percentage of cells between control cells and cells co-trancfected with pcDNA3- fl plus pcDNA3- bax (Lane 4, 14.5\%). bid and bax mRNA were detected in BEL-7404 cells by 35 cycles-RT-PCR analysis (Data not shown). Semi-quantitative RT-PCR analysis (25 cycles) proved overexpression of bid or bax in 7404/b-16 cells co-transfected with pcDNA3- fl plus pcDNA3- bid or pcDNA3- fl plus pcDNA3- bax (Fig 7B). These results indicated that overexpression of Bid but not Bax counteracted the inhibitory effect of Bcl-2 on Fas-mediated apoptosis in human hepatocellular carcinoma cells. 
Bcl-2 inhibited Fas-mediated apoptosis
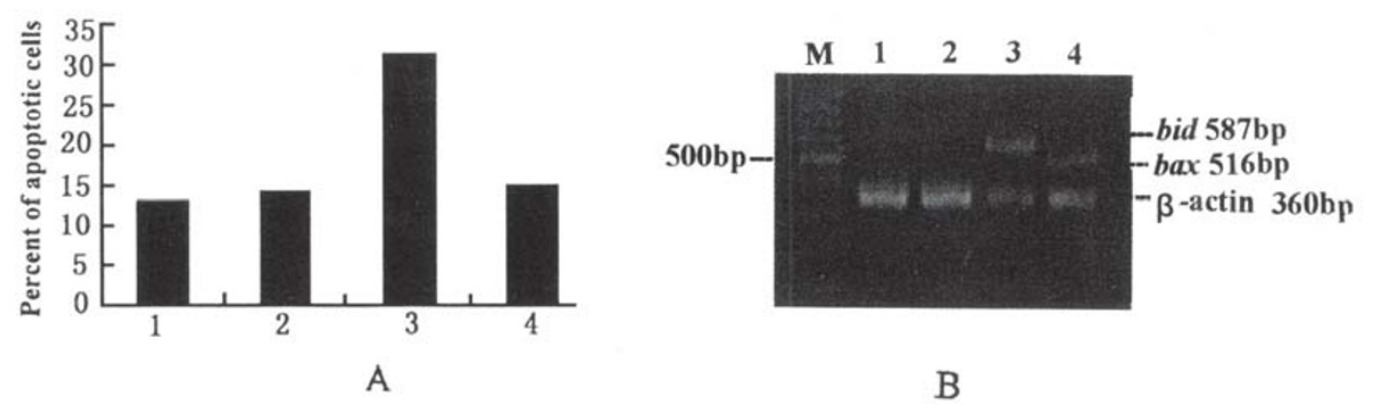

Fig 7. Overexpression of Bid but not Bax counteracted the inhibitory effect of Bcl-2 on Fas-mediated apoptosis in 7404/b-16 cells. A) 7404/b-16 cells were recovered and analyzed by flow cytometry 24 $\mathrm{h}$ after co-transfection with: 1, double amount of pcDNA3. 2. pcDNA3 plus pcDNA3- fl. 3. pcDNA3fl plus pcDNA3- bid. 4. pcDNA3- fl plus pcDNA3- bax. B) RT-PCR (25 cycles for PCR) detection of bid and bax mRNA in cellular total RNA extracted from 7404/b- 16 cells $24 \mathrm{~h}$ after co-transfection with: 1, double amount of pcDNA3. 2. pcDNA3 plus pcDNA3- fl. 3. pcDNA3- fl plus pcDNA3- bid. 4. pcDNA3- fl plus pcDNA3- bax. M was $1 \mathrm{~Kb}$ ladder marker.

\section{DISCUSSOION}

Not only cell proliferation but also programmed cell death (or apoptosis) is involved in the initiation and development of cancer. The elucidation of apoptotic mechanisms will make us to know more about carcinogenesis. The aim of this study is to investigate the effect of Bcl-2 on Fas-mediated apoptosis in human hepatoma cells. We used in this study a human heptocellular carcinoma cell line BEL-7404, which expressed Fas antigen but not FasL and Bcl-2. It was found that transfection with pcDNA3- fl was able to induce cell death in these cells. Fragmentation of cellular nuclei (Fig 2) and formation of typical "DNA ladder"(Fig 4) as well as fasl expression by RT-PCR analysis in these human hepatoma cells transfected with pcDNA3- $\mathrm{fl}$ all suggested that true apoptosis was induced by the binding of FasL and Fas. Flow cytometry analysis indicated that percentage of apoptotic cells reached a maximum $24 \mathrm{~h}$ after transfection (Fig 3). This time point was selected as standard time in later experiments.

Bcl-2 is the mammalian homologue of Ced-9 protein, an apoptosis inhibitor in C. elegans. Its expression can protect cells from apoptosis induced by many signals. Since the expression of Bcl-2 protein was not detected in BEL-7404 cells, we transfected these cells with pcDNA3-bcl-2 and obtained a 7404/b-16 cell line with overexpressed Bcl-2 protein. Apparent apoptosis was induced in BEL-7404 and 7404/neo control cells, but not in 7404/b-16 cells after being transfected with pcDNA3- fl (Fig 6). Although percentage of apoptotic cells in 7404/b-16 cells transfected with control plasmid pcDNA3 (13.1\%) was a little higher than that in 7404 or $7404 /$ neo control cells $(7.1 \%$ or $4.9 \%)$ due to some unknown reasons, these results suggested that the expression of Bcl-2 could inhibit Fas- 
mediated apoptosis in BEL-7404 cells. To date, the mechanism by which Bcl-2 protein inhibits apoptosis is still elusive. Expression of bcl-2 inhibits activation of caspase- 8 and caspase-3, and this activation is necessary for Fas-mediated apoptosis[5]. Bcl-2 protein also regulates release of cytochrome $\mathrm{c}$ via mitochondria pathway[10].

Luo et al. and $\mathrm{Li}$ et al. both found that Bid, a member of Bcl-2 family, might be an intermediate link between Bcl-2 and Fas signaling pathway[11],[12]. Their study suggested that Bid can be cleaved into two parts by active caspase-8 in Fas-mediated apoptosis. The C-terminus of Bid containing BH3 domain has stronger capacity to induce release of cytochrome c, which can, in turn, activated caspase-3. To examine the effect of Bid on Fas-mediated apoptosis in human hepatoma cells, we cloned open reading frame of bid gene and constructed expression plasmid pcDNA3- bid. Transfection with pcDNA3- bid alone did not induce apoptosis in BEL-7404 cells (Data not shown). However, co-transfection with pcDNA3- bid and pcDNA3- fl induced apoptosis in 7404/b-16 cells (Fig 7), which expressed high level of Bcl-2 protein and was resistant to Fas-mediated apoptosis (Fig 6). Moreover we have also shown that overexpression of Bax did not affect Fasmediated apoptosis (Fig 7), although it has been shown to be able to accelerate apoptosis induced by the deprivation of growth factors[7]. These suggested that overexpression of Bid but not Bax counteracted the inhibitory effect of Bcl-2 on Fas-mediated apoptosis. Bid and Bax both are pro-apoptotic proteins, Bid has only BH3 (Bcl-2 homologue 3) domain but $\mathrm{Bax}$ has all of four $\mathrm{BH}$ domains[13]. BH3 domain of Bid or Bax protein forms heterodimers with $\mathrm{BH} 1$ and $\mathrm{BH} 2$ domains of Bcl-2 protein[10]. C-teminus of Bid cleaved by caspases has stronger Bcl-2-binding capacity compared with full length Bid protein [12], but it has not been found that Bax protein can be cleaved by caspases. This may be the cause that overexpression of Bid but not Bax counteracted the inhibitory effect of Bcl2 on Fas-mediated apoptosis. In addition, liver injury is not seen after injection with antiFas antibody in bid-deficient mice, also suggesting that Bid is essential to Fas-induced apoptosis[14].

\section{ACKNOWLEDGMENTS}

We thank Professor Nagata S. (Osaka University Medical School, Japan) for providing plasmid pBX- fl, Professor Korsmeyer SJ. (University of Washington, USA) for providing bax cDNA, Doctor Ying DL. (Shanghai Institute of Cell Biology, Chinese Academy of Sciences) for providing bcl-2 cDNA, and Mr. Xie XH (Shanghai University, China) for taking part in cloning and sequencing of bid ORF.

This work was supported by Major State Basic Reaearch (973) Program of China.

\section{REFRENCES}

[1] Nagata S. Apoptosis by death factor. Cell 1997; 88:355-65.

[2] Chao DT, Korsmeyer SJ. Bcl-2 family: regulators of cell death. Annu Rev Immunol 1998; 16:395-419.

[3] Strasser A, Harris AW, Huang DCS et al. bcl-2 and Fas/APO-1 regulate distinct pathways to lymphocyte apoptosis. EMBO J 1995; 14(24):6136-47. 


\section{Bcl-2 inhibited Fas-mediated apoptosis}

[4] Itoh N, Tsujimoto Y, Nagata S. Effect of bcl-2 on Fas-mediated cell death. J Immunol 1993; 151:62127.

[5] Scaffidi C, Fulda S, Srinivasan et al. Two CD95 (APO-1/Fas ) signaling pathways. EMBO J $1998 ; 17$ (6):1675-87.

[6] Lu SHD. Technologies in morden molecular biology. 1993; PP:345-7. High education press (China).

[7] Zhao H, Xu YH. Mad-overexpression down regulates the maliganant growth and p53 mediated apoptosis n human hepatocellular carcinoma BEL-7404 cells. Cell Research 1999; 9:51-9.

[8] Oltvai ZN, Milliman CL, Korsmeyer SJ. Bcl-2 heterodimerizes in vivo with a conserved homolog, bax, that accelerates programed cell death. Cell 1993; 74:609-19.

[9] Lowe SW, Ruley HE, Jacks T. et al. P53-dependent apoptosis modulates the cytotoxicity of anticancer agents. Cell 1993; 74:957-67.

[10] Yin XM. Signal transduction mediated by bid, a pro-death Bcl-2 family proteins, connects the death receptor and mitochondria apoptosis pathway. Cell Research 2000; 10(3):161-7.

[11] Luo X, Budihardjo I, Zou H et al. Bid, a Bcl-2 interacting protein, mediates cytochrome c release from mitochondria in respone to activation of cell surface death receptors. Cell 1998; 94:481-90.

[12] Li HL, Zhu H, Xu CL. et al. Cleavage of bid by caspase 8 mediates the mitochondrial damage in the Fas pathway of apoptosis. Cell 1998; 94:491-501.

[13] Chao DT, Korsmeyer SJ. BCL-2 family: regulators of cell death. Annu Rev Immunol 1998; 16:395-419.

[14] Yin XM, Wang K, Gross A et al. Bid-deficient mice are resistant to Fas-induced hepatocellular apoptosis. Nature 1999; 400(6747):886-91.

Received May-17-2000. Revised Aug-17-2000. Accepted Aug-21-2000. 